\title{
Drug Prescribing and Dispensing Practices in Tertiary Care Hospital of Eastern Ethiopia: Evaluation with World Health Organization Core Prescribing and Patient Care Indicators
}

\author{
Mekonnen Sisay ${ }^{1^{*}}$, Jemal Abdela ${ }^{1}$, Zenebe $\mathrm{Kano}^{2}$, Meles Araya ${ }^{2}$, Meseret Chemdi ${ }^{2}$ and Amanuel Fiseha ${ }^{2}$ \\ ${ }^{1}$ Department of Pharmacology, School of Pharmacy, College of Health and Medical Sciences, Haramaya University, Harar, Ethiopia \\ ${ }^{2}$ Clinical Pharmacy Unit, Hiwot Fana Specialized University Hospital, Harar, Ethiopia
}

"Corresponding author: Mekonnen Sisay, Department of Pharmacology, School of Pharmacy, College of Health and Medical Sciences, Haramaya University, Harar, Ethiopia, Tel: +251920-21-21-35; Fax: +251-25-666-80-81; E-mail: mekonnensisay27@yahoo.com

Received date: April 29, 2017; Accepted date: May 09, 2017; Published date: May 18, 2017

Copyright: (C) 2017 Sisay M, et al. This is an open-access article distributed under the terms of the Creative Commons Attribution License, which permits unrestricted use, distribution, and reproduction in any medium, provided the original author and source are credited.

\begin{abstract}
Background: Rational prescribing, dispensing and patient use are the major components of rational drug use; however, the actual drug use pattern is not in line with World Health Organization (WHO) guidelines and is often irrational in many healthcare settings, particularly in developing countries. Therefore, this study aimed to highlight general prescribing and dispensing practices at Hiwot Fana Specialized University Hospital (HFSUH) outpatient settings.
\end{abstract}

Method: Across-sectional study design was employed to determine the medication prescribing and dispensing practices at HFSUH. As per the WHO guideline for prescribing encounters, about 600 prescriptions were included in the study. Systematic random sampling was applied to obtain samples from encounters prescribed and dispensed from Jan 1-June 30, 2016. Moreover, as per the minimum requirement of the WHO guideline, 100 patient encounters were also included in the study with convenient sampling method. The data were evaluated against WHO standards for core drug use indicators.

Results: From the total of 600 outpatient prescribing encounters, the prevalence of getting recorded diagnosis was almost negligible $(4.67 \%)$. Only two thirds $(67.60 \%)$ of prescription contain the patient name to whom the drug was prescribed. Coming to the drug related information, the prevalence of getting written dosage forms $(18.5 \%)$, and the total quantity $(35.34 \%)$ were found suboptimal. Duration of treatment had been documented in less than threefourth of encounters $(73.00 \%)$. Regarding the WHO core prescribing indicators, the average number of drugs prescribed per encounter was found to be 1.89. The percentage of encounters that contain at least one antibiotic and injection was $304(50.67 \%)$ and $315(59.16 \%)$, respectively. Besides, the percentage of drugs prescribed by generic name and from an Essential Drug List (EDL) of the country was $1055(93.04 \%)$ and $1134(100.00 \%)$, respectively. The most commonly prescribed antibacterial agents were ceftriaxone $110(36.20 \%)$, metronidazole 52 $(17.11 \%)$, and cloxacillin $27(8.89 \%)$. Besides, the top four prescribed injections were tramadol $214(34.79 \%)$ ceftriaxone $110(17.89 \%)$, furosemide $95(15.45)$ and metronidazole $52(8.46 \%)$. Looking at the patient care indicators, the percentage of drugs actually dispensed and labeled were $86 \%$ and $11 \%$, respectively. The average dispensing time was $59.9 \mathrm{~s}$ and the percentage of patients knowing the entire regimen was $61.88 \%$.

Conclusion: As a tertiary care hospital, the overall completeness and rationality of prescription was found suboptimal since some of the key components were missed. The degree of polypharmacy fell within the window of WHO criteria. However, inappropriate use of antibiotics and injections was highly noticeable (significant deviation from the upper limit of the WHO standard). These are two critical but commonly misused classes of drugs given greater emphasis by WHO. Prescribing practice with generic name and from EDL is highly appreciable in this setting. However, labelling practice has been significantly poor in this setting.

Keywords: Prescribing practice; Dispensing practice; Prescribing indicators; Patient care indicators; Hiwot Fana Specialized University Hospital (HFSUH)

\section{Abbreviations: \\ AMR: Antimicrobial Resistance; EDL: Essential Drug List; GUTRH: Gondar University Teaching and Referral Hospital; HFSUH: Hiwot Fana Specialized University Hospital; HUTRH: Hawassa University Teaching and Referral Hospital; JUSH: Jimma University Specialized Hospital; WHO: World Health Organization}

\section{Introduction}

Rational Drug Use (RDU) generally covers rational prescribing, rational dispensing and rational patient use of medications for variety of medical conditions. It is a cost effective, safe and targeted use of drugs for human and animals. Rational use of drugs will maximize the therapeutic outcomes, reduce adverse drug reactions and drug interactions, shorten the duration of hospital stay and decrease the healthcare costs of patients and settings [1-3]. 
Citation: Sisay M, Abdela J, Kano Z , Araya M, Chemdi M, et al. (2017) Drug Prescribing and Dispensing Practices in Tertiary Care Hospital of Eastern Ethiopia: Evaluation with World Health Organization Core Prescribing and Patient Care Indicators. Clin Exp Pharmacol 7: 238. doi:10.4172/2161-1459.1000238

Page 2 of 8

A drug prescription is usually considered as the endpoint of a patient's visit to a certain healthcare setting. In most situations, it is an instruction that is formally written from a prescriber to a dispenser and is considered to be a medico-legal document that should be written legibly, accurately and completely. Although the prescription format may vary slightly from one country to another, most countries agree on the core elements that should be included in the prescription order. These include patient related details (patient's name, sex, age, weight, date of admission, address, diagnosis), drug related details (drug name, dose, dosage form, strength, frequency, quantity and duration of therapy), and professional details (stamp, signature of prescribers and dispensers) [4].

Rational drug use can partly be achieved when there is a rational prescribing of drugs with generic or non-proprietary name and from an Essential Drugs List (EDL) of the healthcare setting (if any) or from the country at large. For drugs to be considered essential, they should meet the healthcare demands of the majority of the population in that catchment area. They are usually selected based on the prevailing disease condition, risk benefit and cost effectiveness ratio (pharmacoeconomic analysis), quality, patient compliance and acceptance. Drugs prescribed with generic name can also increase the availability and affordability of drugs elsewhere $[5,6]$.

World Health Organization (WHO) has designed standardized core prescribing and patient care indicators to evaluate the trends of drug use in outpatient settings of health facilities. Each core indicators have five components. The prescribing indicators include the degree of polypharmacy, the percentage of drugs prescribed with generic name, the percentage of encounters with at least one antibiotic and injection and the percentage of drugs prescribed from EDL. Moreover, the patient care indicators include, average consultation time, average dispensing time, percentage of drugs actually dispensed and labelled as well as the percentage of patients' who know how to take the correct dosage. The recommended value of WHO for core prescribing indicators include: average number of drugs per encounter $<2$ (1.4-1.8), percent encounters with antibiotics $<30 \%(20-26.8 \%)$, and percent encounters with injection(s) $<25 \%$ (13.4-24.1\%), whereas ideally adopted value for prescribing by generic name and from EDL is $100 \%$ each. Coming to the WHO patient care indicators, the average consultation time ( $>10 \mathrm{~min})$, average dispensing time $(>180 \mathrm{~s})$, and the percentage of drugs actually dispensed, labeled and patient knowledge are all ideally $100 \%$ [7-9].

These indicators measure the performance of prescribers and dispensers in key areas concerning rational drug use. The indicators assess prescribing, dispensing and patient use of drugs based on clinical encounters at healthcare facilities for the treatment of different illnesses. These indicator studies are less useful when used for inpatient care. These indicators can be used in dispensaries, health centers and hospitals in both public and private sector [10].

Prescription studies describing current prescribing practices using the WHO prescribing indicators should have at least 600 encounters included in a cross-sectional survey, with a greater number if possible. Since the clinical encounters cover a wide range of illnesses, the core prescribing indicators assess general prescribing practices independent of specific diagnoses. Moreover, a minimum of 100 patient encounters can be included to evaluate patient care indicators prospectively [10].

\section{Materials and Methods}

\section{Study setting, design and period}

Harari region is one of the nine national regional states of Ethiopia, with the town of Harar as its capital. Harar is located $526 \mathrm{~km}$ away from Addis Ababa to the east. Based on the 2015 Census result of the CSA, Harari has a total population of 183,344 , of which 92,258 were male and 91,086 female; 99,321 or $54.17 \%$ of the population were urban inhabitants. In the region, there are 4 governmental hospitals, 1 NGO and 2 private hospitals, and 8 health centers [11]. Among the governmental hospitals, hospital based cross-sectional study designed was employed to evaluate the current medication prescribing and dispensing practices at Hiwot Fana Specialized University Hospital (HFSUH) during the study period. This study was conducted from July 1-31, 2016 G.C.

\section{Population}

For prescribing indicators study, all prescribing encounters dispensed in outpatient pharmacies of HFSUH were used as a source population for this study. Prescribing encounters dispensed within six months (Jan 1, 2016-Jun 30, 2016) were used as a study population among which samples were drawn for the actual study. Prescribing encounters which were not legible or those containing medical supplies only were excluded during sampling process. What is more, for study of patient care indicators, all ambulatory or outpatient encounters of the hospital were taken as a source population; however, those who attended the outpatient pharmacy with prescription in the study period (Jul 1-Jul 31, 2016) were considered as a study population.

\section{Sample size determination and sampling technique}

Based on the WHO guideline for assessing rationality of drug use in outpatient departments of healthcare settings, at least 600 prescribing encounters can be considered for evaluation of prescribing practice if single healthcare setting is selected [10]. Therefore, to imitate the guideline, 600 prescribing encounters were taken for the study. Within the six months of a study period described earlier, about 11,400 prescriptions was found to be dispensed in outpatient pharmacy. In order to collect the aforementioned sample size, systematic random sampling was employed once sampling frame had been developed by arranging the study population in chronological order of prescription. The sampling interval was calculated by dividing the study population by actual sample size $(\mathrm{Kth}=11,400 / 600=19)$. Hence, the samples were collected by picking every 19th encounter given randomly selected initial sample. Coming to the patient care indicators study, as per the WHO guideline, at least 100 patient encounters can be included in outpatient departments of a single healthcare setting [10]. Therefore, 100 patient encounters were engaged in the actual study. Convenient sampling was employed to enrol participants attending HFSUH outpatient pharmacy during the study period.

\section{Variables}

The dependent variable for this study is drug prescribing and dispensing practices. Independent variables that ultimately affect the medication prescribing practices include knowledge and experience of prescribers, Prescribing indicators (degree of polypharmacy, encounters with antibiotic(s) or injection(s) prescribed (\%), generic prescribing (\%), and prescribing from EDL (\%)) as well as the healthcare environment at large. Dispensing practice can also be 
Citation: Sisay M, Abdela J, Kano Z , Araya M, Chemdi M, et al. (2017) Drug Prescribing and Dispensing Practices in Tertiary Care Hospital of Eastern Ethiopia: Evaluation with World Health Organization Core Prescribing and Patient Care Indicators. Clin Exp Pharmacol 7: 238. doi:10.4172/2161-1459.1000238

Page 3 of 8

affected by average contact time between dispenser and patient (dispensing time), the availability and quality of labelling, the availability of drugs (percentage of dispensed drugs), dispenser-patient communication and interaction, knowledge and experience of dispensers, among others.

\section{Data collection procedures}

Data were collected both retrospectively and prospectively with the help of observational checklists. Data abstraction format that includes all the components of prescription (patient related, drug related and professional related data), prescribing indicator form and patient care indicator forms were utilized during the study. Prescribing indicator form was designed and adopted by WHO but with slight modification for ease of collecting all necessary data that might be left unaddressed by the indicator form alone. All the necessary information contained in the individual prescribing encounters was recorded in data collection formats (checklists) accordingly. Moreover, the dispensing practice, in association with WHO patient care indicators, was assessed prospectively with the help of WHO observational checklist (patient care indicator form). Among these indicators, the percentage of patient knowledge on how to follow the right dosage regimen was collected with the aid of qualitative study (interview guide that includes name, dose, frequency, duration and reason of treatment). Trained data collectors (Pharmacy personnel) were involved to shoulder the overall data collection process and effectively discharge their tasks. Principal investigator guided and supervised the data collection on daily basis.

\section{Data quality control}

Pre testing was done to check whether the data collection format was valid and reliable. The data were checked and cleared every day for ensuring completeness and consistency before undergoing data processing and analysis.

\section{Data processing and analysis}

The data were entered and processed with SPSS version 16. For indicators study, analysis was done according to the guideline set by WHO for of healthcare outpatient settings [10]. The completeness of prescription was evaluated against the standard. What is more, the actual results of the prescribing and patient care indicators, in this study, were compared with criteria set by WHO for outpatient settings of tropical countries. Moreover, to gauge the drug utilization performance of this hospital, indices for rational prescribing and rational patient care indicators were calculated accordingly. The optimal values of all indicator studies were standardized to 1 [12-14]. Among the prescribing indicators, indices for non-polypharmacy, rational antibiotic utilization and injection safety were calculated by formula (1)

$$
\text { Index }=\frac{\text { optimal value (standard) }}{\text { Observed value (actual setting) }}(1)
$$

The indices for rest prescribing indicators (for generic and essential drug prescribing status) and patient cared indicators (dispensing time, drugs actually dispensed, actually labeled, and patient knowledge) can be calculated using formula (2).

$$
\text { Index }=\frac{\text { Observed value (actual setting) }}{\text { optimal value (standard) }}(2)
$$

\section{Results}

As per the WHO guideline for single healthcare setting, 600 outpatient prescribing encounters were included in this study. Initially, the completeness of individual prescription was assessed accordingly before the prescribing indicator study. In the study, all (100\%) prescription papers were found to be standard. Date of prescription was written for about 550 (91.67\%) prescriptions. Two-thirds of prescriptions were found to have the targeted patient name to which the drug was prescribed. Even though, good prescribing practice was observed regarding sex $(90.17 \%)$, age $(88.6 \%)$ and medical registration number $(93.5 \%)$, significantly poor recording practices were observed in weight $(2.50 \%)$, diagnosis (4.67\%) and address of patients (5.00\%) in this study (Figure 1).

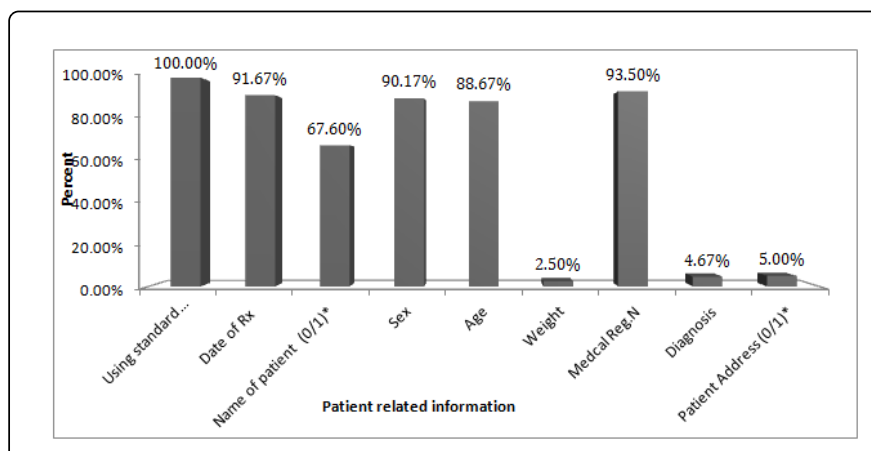

Figure 1: Completeness of patient related information in prescriptions dispensed from Jan 1, 2016-June 30, 2016 at HFSUH outpatient pharmacy.

Looking at the drug related information, the name of the drug was written in all (100\%) prescriptions. More than $510(85 \%)$ prescriptions had the dose of the drug $(87.33 \%)$, route $(85.67 \%)$ and frequency (85.0\%) of administration. Almost three-fourth of prescription also contain the duration of treatment. Poor prescribing practice was observed in writing the dosage form of the drug (18.5\%) and the total quantity (35.34\%) to be taken during the course of treatment (Figure 2).

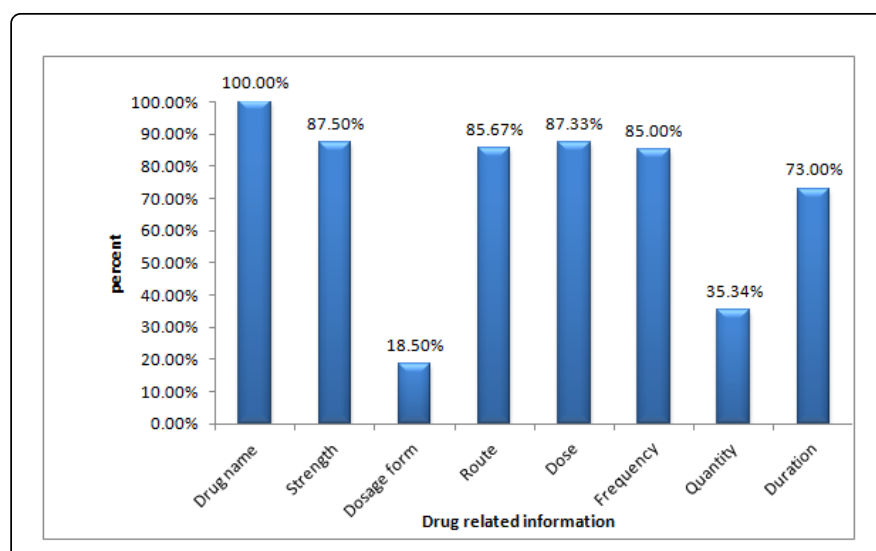

Figure 2: Drug related information in prescriptions dispensed from Jan 1, 2016-June 30, 2016 at HFSUH outpatient pharmacy. 
Citation: Sisay M, Abdela J, Kano Z , Araya M, Chemdi M, et al. (2017) Drug Prescribing and Dispensing Practices in Tertiary Care Hospital of Eastern Ethiopia: Evaluation with World Health Organization Core Prescribing and Patient Care Indicators. Clin Exp Pharmacol 7: 238. doi:10.4172/2161-1459.1000238

Page 4 of 8

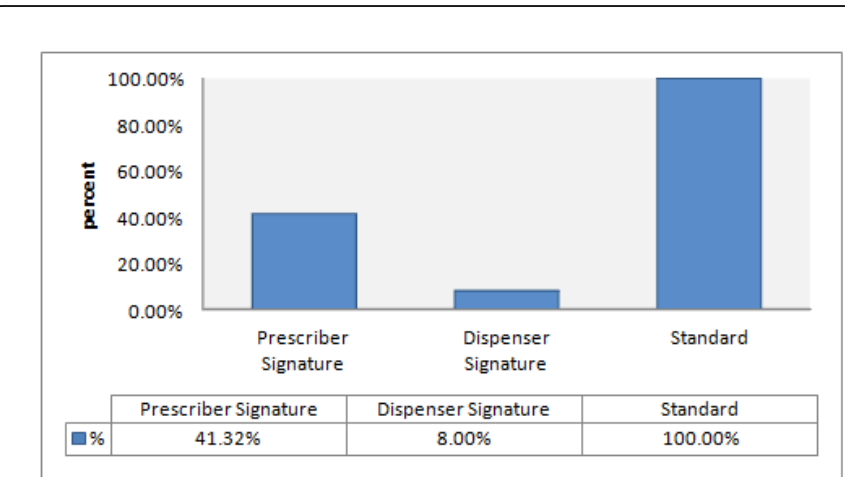

Figure 3: Prescribing and dispenser information in prescription dispensed from Jan 1, 2016-Jun 30, 2016 at HFSUH outpatient pharmacy.
The third section of prescription is about professionals' related information in general. In this section, the prevalence of prescribers' signature was found below half of the prescriptions dispensed in outpatient pharmacy setting 248 (41.32). The dispenser signature was found minimal $48(8.00 \%)$ (Figure 3$)$.

Concerning the degree of poly-pharmacy in this outpatient settings, majority of the prescribing encounters actually contain one drug 257 (42.83\%) followed by two drugs 197 (32.83\%) and three drugs 109 (18.17\%) per prescription. Five and above drugs were subjected to be prescribed in $9(1.5 \%)$ of prescriptions. Generally, from the total of 600 prescribing encounters dispensed in the study period, about 1134 drugs were prescribed (Table 1). Therefore, the average number of drugs per encounter was found to be to 1.89 (Table 2).

\begin{tabular}{|c|c|c|}
\hline Number of drugs per prescription & \# of prescribing encounters & $\%$ \\
\hline One & 257 & 42.83 \\
\hline Two & 197 & 32.83 \\
\hline Three & 109 & 18.17 \\
\hline Four & 28 & 4.67 \\
\hline Five and above & 9 & 1.5 \\
\hline Total encounters & 600 & 100 \\
\hline
\end{tabular}

Table 1: Average number of drugs per encounter and number of drugs per prescription dispensed from Jan 1, 2016-Jun 30, 2016 at HFSUH outpatient pharmacy.

\begin{tabular}{|c|c|c|c|}
\hline WHO core prescribing indicators & Observed values (HFSUH) & WHO standard & Index for RDP (IRDP) \\
\hline Average number of drugs per encounter & $1.89^{*}$ & $<2(1.6-1.8)$ & $1.00 \mathrm{a}$ \\
\hline Drugs prescribed with generic name & $1055(93.04 \%)$ & $100 \%$ & 0.93 \\
\hline Encounters with antibiotic(s) prescribed & $304(50.67 \%)$ & $<30 \%(20.0-26.8 \%)$ & 0.59 \\
\hline Encounters with injection(s) prescribed & $355(59.16 \%)$ & $<25 \%(13.4-24.1 \%)$ & 0.42 \\
\hline Drugs prescribed from EDL & $1134(100 \%)^{*}$ & $100 \%$ & $1.00 \mathrm{a}$ \\
\hline
\end{tabular}

Table 2: Evaluation of WHO core prescribing indicators from Jan 1, 2016-Jun 30, 2016 at HFSUH outpatient pharmacy. ${ }^{*}$ Within WHO standard; IRDP:Index for Rational Drug Prescribing; a: Optimal prescribing values

Coming to the rest four WHO core prescribing indicators, the percentage of encounters with antibiotics (antibacterial agents) and injections prescribed were found to be 304 (50.67\%) and 355 (59.16\%), respectively. Besides, the percentage of drugs prescribed with generic name and from essential drug list of the country were 1055 (93.04\%) and $1134(100 \%)$, respectively. In this study, the upper limits of WHO standard for percent encounters with antibiotics and injections were considered for tropical countries and are $30 \%$ and $25 \%$, respectively. Looking at the indices for rational drug prescribing, the indices for non poly pharmacy, generic prescribing, rational antibiotic usage, injection safety, and essential dug prescribing were 1.00, 0.93, 0.59, 0.42 and 1.00 , respectively. The overall drug prescribing index was found to be 3.94 out of 5.00 (Table 2).

In this study, from the total antibacterial agents, the most common antibacterial agent prescribed was found to ceftriaxone 110 (36.20\%) followed by metronidazole $51(17.11 \%)$, cloxacillin $(8.89 \%)$, crystalline penicillin 23 (7.56\%), ciprofloxacin and gentamicin, each 20 (6.57\%), and cortimoxazole $16(5.26 \%)$ (Table 3$)$. Coming to the prevalence of injections in the prescribing encounters under study, the most commonly prescribed injections were tramadol 214 (34.79\%), ceftriaxone 110 (17.89\%), furosemide 95 (15.45), metronidazole 52 
Citation: Sisay M, Abdela J, Kano Z , Araya M, Chemdi M, et al. (2017) Drug Prescribing and Dispensing Practices in Tertiary Care Hospital of Eastern Ethiopia: Evaluation with World Health Organization Core Prescribing and Patient Care Indicators. Clin Exp Pharmacol 7: 238. doi: $10.4172 / 2161-1459.1000238$

Page 5 of 8

(8.46\%), and metoclopramide $41(6.67 \%)$, tetanus antitoxin 31 (5.04\%), and crystalline penicillin 23 (3.74\%) (Table 4).

\begin{tabular}{|l|l|l|}
\hline Commonly prescribed antibacterial agents & Frequency & $\%$ \\
\hline Ceftriaxone & 110 & 36.2 \\
\hline Metronidazole & 52 & 17.11 \\
\hline Cloxacillin Sodium & 27 & 8.89 \\
\hline Penicillin G Sodium Crystalline & 23 & 7.56 \\
\hline Ciprofloxacin & 20 & 6.57 \\
\hline Gentamicin & 20 & 6.57 \\
\hline Sulphamethoxazole+Trimethoprim & 16 & 5.26 \\
\hline Ampicillin Sodium & 15 & 4.93 \\
\hline Amoxicillin & 11 & 3.62 \\
\hline Doxycycline & 10 & 3.29 \\
\hline Total & 304 & 100 \\
\hline
\end{tabular}

Table 3: Frequency distributions of antibiotics prescribed at HFSUH from Jan 1, 2016-Jun 30, 2016 at HFSUH outpatient pharmacy.

\begin{tabular}{|l|l|l|}
\hline Commonly prescribed Injections & Frequency & $\%$ \\
\hline Tramadol & 214 & 34.8 \\
\hline Ceftriaxone & 110 & 17.9 \\
\hline Furosemide & 95 & 15.5 \\
\hline Metronidazole & 52 & 8.46 \\
\hline Metoclopramide & 41 & 6.67 \\
\hline Tetanus antitoxin (TAT) & 31 & 5.04 \\
\hline Crystalline penicillin & 23 & 3.74 \\
\hline Gentamicin (80 mg/2 ml) & 20 & 3.25 \\
\hline Ampicillin Sodium (500 mg/Vial) & 15 & 2.44 \\
\hline Cloxacillin Sodium-Injection 500 mg & 14 & 2.28 \\
\hline Total & 615 & 100 \\
\hline
\end{tabular}

Table 4: Frequency distributions of injection prescribed at HFSUH from Jan 1, 2016-Jun 30, 2016 at outpatient pharmacy.

Looking at the patient care indicators, about 247 drugs were prescribed for 100 patient encounters included in the study and from which 212 drugs were actually dispensed within the hospital pharmacy (86\%). Among the dispensed drugs within the setting, about $23(11 \%)$ drugs were actually labeled by the dispensers. In this study, the average contact time between dispenser and patient (dispensing time) excluding the time required for billing was found to be $59.9 \mathrm{~s}$. Regarding the patient knowledge, the overall patient knowledge of the dosage regimen or course of treatment was found to be $61.88 \%$. Generally, the indices for dispensing time, actually dispensed drugs, labelling status and patient knowledge were $0.33,0.86,0.11$ and 0.62 , respectively (Table 5).

\begin{tabular}{|c|c|c|c|c|}
\hline \multicolumn{2}{|c|}{ Patient care indicators } & HFSUH & $\begin{array}{l}\text { WHO } \\
\text { standard }\end{array}$ & $\begin{array}{l}\text { Index for } \\
\mathrm{PCl}\end{array}$ \\
\hline \multicolumn{2}{|c|}{ Number of drugs prescribed } & 247 (a) & - & - \\
\hline \multicolumn{2}{|c|}{ Number of drugs dispensed } & $212(b)$ & - & - \\
\hline \multicolumn{2}{|c|}{ Number of labelled drugs } & $23(\mathrm{c})$ & - & - \\
\hline \multicolumn{2}{|c|}{$\begin{array}{l}\text { Percentage of drugs actually } \\
\text { dispensed }\end{array}$} & $\mathrm{b} / \mathrm{a}(86 \%)$ & $100 \%$ & 0.86 \\
\hline \multicolumn{2}{|c|}{$\begin{array}{l}\text { Percentage of drugs actually } \\
\text { labelled }\end{array}$} & $\mathrm{c} / \mathrm{b}(11 \%)$ & $100 \%$ & 0.11 \\
\hline \multicolumn{2}{|c|}{ Average dispensing time } & $59.90 \mathrm{~s}$ & $>180 \mathrm{~s}$ & 0.33 \\
\hline \multirow{7}{*}{$\begin{array}{l}\text { Patient } \\
\text { knowledge of } \\
\text { how to take the } \\
\text { correct dosage }\end{array}$} & Name of drug(s) & 60 & - & - \\
\hline & Indication & 50 & - & - \\
\hline & Dose & 80 & - & - \\
\hline & Frequency & 95 & - & - \\
\hline & Duration & 80 & - & - \\
\hline & $\begin{array}{l}\text { Special information } \\
\text { about drugs }\end{array}$ & 20 & - & - \\
\hline & $\begin{array}{l}\text { Average patient } \\
\text { knowledge }\end{array}$ & $61.88 \%$ & $100 \%$ & 0.62 \\
\hline
\end{tabular}

Table 5: Evaluation of dispensing practice with WHO patient care indicators at HFSUH outpatient setting from July 1-July 31.PCI:Patient Care Indicator

\section{Discussion}

This study included the overview of rationality and completeness of prescription papers beyond evaluation of WHO core drug use indicators. From the total of 600 prescribing encounters included in the study, the prevalence of getting diagnosis was almost negligible. Around two thirds of prescription contains the patient name to which the drug was prescribed. Coming to the drug related information, the prevalence of prescription with dosage forms and the total quantity used in the course of treatment were found suboptimal. Duration of treatment had been documented in less than three-fourth of encounters. The legality, validity, reliability and completeness of prescription papers have overwhelming influence on rational utilization of drugs throughout the globe [15]. However, prescribers have often used prescription in the wrong way. Missing the duration of therapy might result under therapy or over therapy. Under therapy in turn commonly results in the development of resistance and prolonged hospital stay. Over therapy, on the other hand, may result in toxicological concerns, super infections, and wastage of resources. The age of the patient is also vital to rule out contraindication (if any) and to adjust dosage regimen. Missing the patient name usually mislead the dispensers by issuing the drug to the wrong patient. In this study, almost all prescriptions don't contain diagnosis. The prescribers often omit writing the diagnosis on the prescription paper [16]. In the absence of diagnosis, the dispensers simply supply drugs without any know how about the condition to which the drug is going to be issued. Better than this study was recorded in other setting where the doses of medications were missed only in $1.01 \%$ of prescriptions while the duration of treatment was missed in $14.9 \%$ [17]. 
Citation: Sisay M, Abdela J, Kano Z , Araya M, Chemdi M, et al. (2017) Drug Prescribing and Dispensing Practices in Tertiary Care Hospital of Eastern Ethiopia: Evaluation with World Health Organization Core Prescribing and Patient Care Indicators. Clin Exp Pharmacol 7: 238. doi: $10.4172 / 2161-1459.1000238$

Page 6 of 8

Looking at the WHO core prescribing indicators, the average number of drugs per encounter (degree of pharmacy) was found to be 1.89. This value normally falls within the window of WHO standard which mandates the degree of poly-pharmacy be less than or equal to two (ideally, 1.6-1.8) in outpatient settings [10]. Even if it lies near to the upper boundary, this finding is highly appreciable considering developing country where the healthcare delivery is often erratic. However, lower average numbers of drugs per encounter $(1.7,1.76,1.8$, and 1.8) were documented in different parts of Ethiopia including southern Ethiopia [18], Gondar University Teaching and Referral Hospital (GUTRH) [19], Jimma University Specialized Hospital (JUSH) [20], and Dessie Referral Hospital [21], respectively. On the contrary, more than this value was recorded in different parts of the world including $2.4( \pm 0.7)$ in United States [17], 2.31 in India [22], 2.1 in west Ethiopia [23], 2.2 in Somali region of eastern Ethiopia [24], 2.3 in Pakistan [25] and 4.89 in Bangladesh [26]. Even if the degree of poly-pharmacy seems safe in this study, it requires close monitoring so as to keep the current prescribing practice. The higher degree of polypharmacy may result in greater risk of adverse drug reactions, drugdrug interactions and extravagancy prescribing [10].

Coming to the generic prescribing practice, the percentage of drugs prescribed with generic name was found to be $93.04 \%$ in this study. This value is slightly lower than the ideal WHO standard (100\%) [10] In various outpatient settings around the globe, higher and closer to the standard values were reported such as $99.16 \%$ in GUTRH [19], 95.8\% in four hospitals of southern Ethiopia [27], 98.7\% in Hawassa University Teaching and Referral Hospital (HUTRH) [28], and $94.9 \%$ in Ayder referral hospital, Northern Ethiopia [29]. On the other hand, fewer values were documented in other health care settings including $83.1 \%$ in Pakistan [25] and 79.2\% in southern Ethiopia. Oddly enough, extremely poor generic prescribing practices were also reported in some settings such as $0.5 \%$ and $0.05 \%$ in Indian healthcare settings $[22,30]$ and $0.0 \%$ in tertiary care hospital of Bangladesh [26]. Being generic is one of the criteria for essential drugs selection. In lowincome countries like Ethiopia where resources are often scarce, generic prescribing has several advantages: Generic drugs are relatively affordable, accessible, and recallable compared to brand counterparts [10].

Major drug use areas given major emphasis by WHO indicator studies are encounters with antibiotic(s) and injection(s) [10]. The percentage of encounters with antibiotics prescribed was found to be $50.67 \%$ which is too much higher than the upper limit of WHO standard, 30\% (ideal range, 20-26.8\%)[10]. Values that are lower than this finding and closer to the WHO standard were reported from different areas of the globe including $30.3 \%$ and $31.8 \%$ in Indian healthcare settings [22,30], 29.14\% and $31.8 \%$ in GUTRH and Bahir Dar, respectively, Ethiopia [19,31]. However, several reports indicated that the prevalence of prescriptions containing antibiotics is even more than this finding. These percentages include $63 \%$ in Sudan [32], 56\% in Uganda [33], 52.4\% in Pakistan [25], 78\% in Bangladesh [26], 54.7\% in four selected hospitals of west Ethiopia [23] and 58.1\% in HUTRH [28].

Besides, the most commonly prescribed antibacterial agent was ceftriaxone $(36.20 \%)$, followed by metronidazole $(17.11 \%)$, and cloxacillin (8.89\%). Research conducted in Bahawal Victoria Hospital, Pakistan indicated that cephalosporins were the most commonly prescribed class of antibiotics (81.5\%) followed by penicillin's $(6.4 \%)$ and fluoroquinolones (6.2\%). Among the individual antibiotics, ceftriaxone contributed the highest percentage share at $71.8 \%$ followed by cefotaxime (5.6\%) and metronidazole (4.7\%) [25]. Similarly, finding from Ayder referral hospital, Tigray region, northern Ethiopia showed that he most commonly prescribed antibiotics were ceftriaxone (19.6\%), gentamicin (15.8\%) and ampicillin (14.7\%) [29]. Apart from this, the most commonly prescribed antibiotics were amoxicillin (16.4\%), ampicillin (15\%), gentamicin (14.9\%) and chloramphenicol (11.6\%) in HUTRH, southern Ethiopia [28]. Inappropriate utilization of antibiotics has come with a significant concern for our globe. Empirical use of this agents is associated with significant resistance concerns in various healthcare settings [10,34]. If things are continued in this way, we are rushing to a post antibiotic era that all the current antimicrobial agents become historical. WHO 2014 report on global surveillance of antimicrobial resistance (AMR) reveals that "antibiotic resistance is no longer a prediction for the future; it is happening right now, across the world, and is putting at risk the ability to treat common infections in hospitals and the community at large". Appropriate use of antibiotics is, therefore, necessary to prevent emergence of drugresistant bacteria as well as to minimize unnecessary wastage of scarce resource in developing countries [34].

Coming to the injection prescribing practice, the prevalence of prescription containing injections was found to too high $(59.16 \%)$ compared to WHO criteria which is generally less than $25 \%$ (ideal range, 13.4-24.1\%) [10]. This finding is more than twice the upper limit of the standard (injection safety index $=0.42$ ). Better injection prescribing practices were reported from several studies $(5.7 \%, 28.50 \%$, $17.18 \%, 28.3 \%$ and $38.1 \%$ ) in India [22], GUTRH, northwest Ethiopia [19], tertiary care hospital of Bangladesh [26], four selected hospitals of west Ethiopia [23] and HUTRH, southern Ethiopia [28], respectively. On the contrary, higher prevalence of injections was also reported in outpatient setting of Bahawal Victoria Hospital of Pakistan (98.0\%) [25]. In developing countries, up to $56 \%$ of primary care patients receive injections. From this, over $90 \%$ may be medically unnecessary. Globally, 15 billion injections are given, but half of these injections do not use sterilized needle and syringe, which may result in transmission of potentially infectious diseases. Infections attributable to unsafe injection are hepatitis B (33\%), hepatitis C (42\%), and HIV (2\%) $[1,35]$. Overuse of injections may come from psychological dependence of both patients and healthcare professionals on injections for most diseases. Patients may preferably seek injections to other safer alternatives for alleviating or treating their healthcare conditions assuming that injections are more effective than any other agents. Indeed, injections are important formulations in certain critical situations including emergency situations due to their fast onset of action, when other alternative are not feasible or cannot absorb from extra vascular route. However, they are not without drawbacks. Frequent use of injections will result in psychological and physiological pain during injection; risk of transmission of infectious biohazards and wastage of resources (increased out of pocket expenditure), among others [10].

The last prescribing indicator included in the study was percentage of drugs prescribed from EDL of the country. This value has completely adhered to the WHO adopted standard (100\%) [10]. However, values that are lower than this finding were documented in various settings such as $94.7 \%$ in United States [17], 53\% in India [22], 81.5\% in Pakistan [25], 96.6\% in southern Ethiopia [28] and 95.2\% in northern Ethiopia healthcare setting [29]. Prescribing from the EDL has a plenty of advantages. Essential drugs are the one that are selected by criteria including generic version, consideration of drugs of choice for the prevailing health condition in the catchment area or country, cost effectiveness ratio, quality, safety (risk-benefit aspect) and other 
Citation: Sisay M, Abdela J, Kano Z , Araya M, Chemdi M, et al. (2017) Drug Prescribing and Dispensing Practices in Tertiary Care Hospital of Eastern Ethiopia: Evaluation with World Health Organization Core Prescribing and Patient Care Indicators. Clin Exp Pharmacol 7: 238. doi:10.4172/2161-1459.1000238

Page 7 of 8

pharmacokinetic considerations [10,35]. Therefore, prescribing from EDL maximizes affordability and availability of drugs, reduces the possibility of drug interaction and adverse drug reactions and ultimately promotes therapeutic outcome.

Looking at the patient care indicators, the average dispensing time was calculated to be $59.9 \mathrm{~s}$. This value is below one third of the WHO set point [10]. Moreover, longer dispensing time was reported in different settings. For example, $96.1 \mathrm{~s}( \pm 52.0)$ to $152.3 \mathrm{~s}( \pm 47.6)$ in four hospitals of southern Ethiopia [36], $105 \mathrm{~s}$ in average of ten countries [37,38], $150 \mathrm{~s}$ in Zimbabwe [39] and $201 \mathrm{~s}$ in Nigerian healthcare settings [40]. The duration of dispensing time ultimately affects the level of comprehension of patients towards the course of treatment. The shorter the dispensing time the poorer the patient knowledge on following the dosage regimen will be [10]. Besides, the percentage of drugs actually dispensed and labeled were $86 \%$ and $11 \%$, respectively. Both of these indicators are lower than the ideal WHO standard (100\%) [10]. The percentage of dispensed drugs was found similar with the average percent values of four hospitals in southern Ethiopia $(86.3 \%)$. However, the percentage of labeled drugs in this study was much lower than the aforementioned setting (45.4\%) [36]. The availability of essential drugs in the dispensary of healthcare settings is one indicator for quality of care. If there is high level of stock out drugs, at the end of the day, the patient confidence on the healthcare system gradually erodes since they go to the private retail outlets to purchase drugs at costly price. Surprisingly, as observed in the study, drugs that have been dispensed in the outpatient pharmacy are not adequately labeled. Labelling is one of the key indicators of good dispensing practice and by any means, adequate labelling ultimately promotes patient awareness about the regimen he/she takes and hence increases treatment adherence [10]. The percentage of patient knowledge on this study was found to be $61.88 \%$. This value is lower than other studies such as $70 \%$ in Zimbabwe [39] and $78.8 \%$ in southern Ethiopia [36]. The patient knowledge may fade further when the time goes on as expected from the quality of dispensing. Therefore, since it is an immediate awareness just after dispensing, no one can conclude that this knowledge persists throughout the course of therapy.

\section{Limitations of the study}

This indicator studies highlight general drug use problems at the individual level. However, they do not link each drug with diagnosis. They are used to undergo quantitative studies and indicate major problem areas of drug use. They indicate where the problem exists but don't answer why it exists.

\section{Conclusion}

As a tertiary care hospital, the overall completeness and rationality of prescription was found suboptimal since some of the key components were missed. The degree of polypharmacy falls within the window of WHO criteria. However, inappropriate use of antibiotics and injections was highly noticeable. These are two critical but commonly misused classes of drugs given greater emphasis by WHO. Prescribing practice with generic name and from EDL is highly appreciable in this setting. However, labelling practice has been significantly poor in this setting. Generally, considering such irrational drug use in majority of the WHO core drug use indicators study, further in-depth investigation (drug use evaluation and qualitative studies) is warranted to dig out the underlying problem and hence interventional strategies can be designed to redirect the current drug use pattern. Among the strategies, educational strategies (training and awareness creation programs), managerial strategies (developing drug and therapeutic committee (DTC) and drug information centers (DIC)), economical strategies (extra payment and rewards for those who perform better) and regulatory strategies (avoiding perverse financial incentives in brand prescribers, controlling promotional issues) can be implemented to somehow promote rational drug use.

\section{Declarations}

\section{Ethical approval and consent to participate}

Permission was sought and obtained from the administrator of HFSUH prior to starting the actual study. Moreover, participant information sheet and informed consent form was filled to collect data regarding patient care indicators from the individual patient. Confidentiality was assured for all information collected.

\section{Availability of data and materials}

All the data were actually contained within the manuscript.

\section{Funding}

No specific grant for this study.

\section{Authors' contribution}

$\mathrm{ZK}, \mathrm{MA}, \mathrm{MC}$, and AF were involved in the conception of the original idea, helped to draft the proposal; all authors participated in implementation stages of the study and initial write up; MS, JA and ZK coordinated the data collection process. MS also analyzed and wrote the research outputs and prepared the final manuscript for publication. All authors read and approved the final version of the manuscript.

\section{Competing interests}

The authors have declared that there is no competing interest.

\section{Acknowledgment}

We would like to provide a deepest gratitude and appreciation for HFSUH staffs for their kindly support.

\section{References}

1. Management Sciences for Health (MSH) (1997) Managing drug supply (2nd edn.). Kumarian Press, West Hart Ford, Conn, USA.

2. Laing RO, Hogerzeil HV (2001) Ten recommendations to improve use of medicines in developing countries. Health Policy Plan 16: 13-20.

3. Drug Administration and Control Authority (DACA) (2003) Training modules on operation and management of special pharmacies. Birnanenaselam Printing Enterprise, Ethiopia.

4. Belknap SM, Moore H, Lanzotti SA, Yarnold PR, Getz M, et al. (2008) "Application of software design principles and debugging methods to an analgesia prescription reduces risk of severe injury from medical use of opioids". Clin Pharmacol Therapeut 84: 385-392.

5. Ofori-Asenso R, Brhlikova P, Pollock AM (2016) Prescribing indicators at primary health care centers within the WHO African region: a systematic analysis (1995-2015). BMC Public Health 16: 724.

6. Tsega B, Makonnen E (2012) Comparative evaluation of drug prescription appropriateness in public and private health institutions of south west Ethiopia: The case of Wolkite Town. IJPSR 3: 4922-4928. 
Citation: Sisay M, Abdela J, Kano Z , Araya M, Chemdi M, et al. (2017) Drug Prescribing and Dispensing Practices in Tertiary Care Hospital of Eastern Ethiopia: Evaluation with World Health Organization Core Prescribing and Patient Care Indicators. Clin Exp Pharmacol 7: 238. doi:10.4172/2161-1459.1000238

Page 8 of 8

7. World Health Organization (WHO). Introduction to Drug Utilization Research. Oslo, Norway: WHO International Working Group for Drug Statistics Methodology, WHO Collaborating Centre for Drug Statistics Methodology, WHO Collaborating Centre for Drug Utilization Research and Clinical Pharmacological Services; 2003.

8. World Health Organization and University of Amsterdam (2004) How to Investigate the Use of Medicines by Consumers. Geneva, Switzerland: World Health Organization and University of Amsterdam.

9. WHO (1993)Action program on essential drugs. How to Investigate Drug Use in Health Facilities. G eneva, Switzerland: WHO Pp: 9-31.

10. World Health Organization (WHO) (1993) How to investigate drug use in health facilities: selected drug use indicators, action program on essential drugs (DAP). Geneva.

11. Central statistics agency (CSA) (2015) Ethiopia.

12. Zhang Y, Zhi M (1995) Index system, appraising method for comprehensive appraisal. J North Jiaotong Univ 19: 393-400.

13. El Mahalli A (2012) WHO/INRUD drug prescribing indicators at primary health care centers in Eastern province, Saudi Arabia. East Mediterr Health J 18: 1091-1096.

14. Atif M, Sarwar MR, Azeem M, Umer D, Rauf A, et al. (2016) Assessment of WHO/INRUD core drug use indicators in two tertiary care hospitals of Bahawalpur, Punjab, Pakistan. J Pharm Policy Pract 9.

15. West SL, Strom BL, Freundlich B, Norman E, Koch G, et al. (1994) Completeness of prescription recording in outpatient medical records from a health maintenance organization. J Clin Epidemiol 47: 165-171.

16. Kumari R, Idris MZ, Bhushan V, Khanna A, Agrawal M, et al. (2008) Assessment of prescription pattern at the public health facilities of Lucknow district. Indian J Pharmacol 40: 243.

17. Alkot M, Shaheen H, Hathout H (2011) Prescribing patterns and errors in family practice: a retrospective study of prescribing records. J Am Sci 7: 186-190.

18. Dilbato DD, Kuma ZG, Mariam S (1998) A base line survey on prescribing indicators and the underlying factors influencing prescribing in southern Ethiopia. Ethiop J Health Dev 12: 87-93.

19. Admassie E, Begashaw B, Hailu W (2013) Assessment of drug use practices and completeness of prescriptions in gondar university teaching referral hospital. IJPSR 4: 265-275.

20. Ayen WY (2005) Base line survey on drug prescribing indicators for outpatient in Jimma University specialized hospital in South west Ethiopia. Ethiop J Health Sci 15: 147-156.

21. Assen A, Abrha S (2014) Assessment of drug prescribing pattern in Dessie Referral Hospital, Dessie. Int J Pharm Sci Res 5: 77-81.

22. Prakash PDS, Rao VU, Kokiwar PR, Sowmya S, Vishweshwaran G (2016) A Study to evaluate rationality behind prescription patterns using world health organization prescribing indicators. Indo Am J Pharmaceut Res 6.

23. Lenjisa JL, Fereja TH (2014) A retrospective analysis of prescribing practices through WHO prescribing indicators at four selected hospitals of West Ethiopia. J Bioanal Biomed 6: 29-32.

24. Bilal AI, Osman ED, Mulugeta A (2016) Assessment of medicines use pattern using World Health Organization' s prescribing, patient care and health facility indicators in selected health facilities in eastern Ethiopia. BMC Health Serv Res 16: 144.
25. Atif M, Azeem M, Sarwar MR, Shahid S, Javaid S, et al. (2016) WHO/ INRUD prescribing indicators and prescribing trends of antibiotics in the Accident and Emergency Department of Bahawal Victoria Hospital, Pakistan. Springer Plus 5: 1928.

26. Sultana F, Rahman A, Paul TR, Sarwar MS, Islam AU, et al. (2015) Prescribing pattern and prescription errors: a study at a tertiary care hospital of Bangladesh. Bang Pharmaceut J 18: 20-24.

27. Summoro TS, Gidebo KD, Kanche ZZ, Woticha EW (2015) Evaluation of trends of drug-prescribing patterns based on WHO prescribing indicators at outpatient departments of four hospitals in southern Ethiopia. Drug Design Dev Ther 9: 4551-4557.

28. Desalegn AA (2013) Assessment of drug use pattern using WHO prescribing indicators at Hawassa University teaching and referral hospital, south Ethiopia: a cross sectional study. BMC Health Services Research 13: 170.

29. Mezgebe HB, Tadesse B, Legesse B (2015) Antibiotics prescribing pattern in pediatric unit of Ayder referral hospital, Tigray region, Northern Ethiopia. J Sci Innov Res 4: 57-60.

30. Chandelkar UK, Rataboli PV (2014) A study of drug prescribing pattern using WHO prescribing indicators in the state of Goa, India. Int J Basic Clin Pharmacol 3: 1057-1061.

31. Gebeyehu E, Bantie L, Azage M (2015) Inappropriate use of antibiotics and its associated factors among urban and rural communities of bahir dar city administration, Northwest Ethiopia. PLoS ONE 10.

32. Bannenberg WJ, Forshaw CJ, Fresle D, Salami AO, Wahab HA (1991) Evaluation of the Nile province essential drug project. WHO: Geneva; WHO/DAP/91.10. In: How to investigate drug use in health facilities. Geneva: WHO.

33. Christensen RF (1990) A strategy for the improvement of prescribing and drug use in rural health facilities in Uganda. Ugandan Essential drugs and management program; How to investigate drug use in health facilities. Geneva: WHO; 1993. 74 (WHO/DAP/93.1).

34. WHO (2014) Antimicrobial Resistance, Global Report on Surveillance. Geneva, Switzerland: WHO.

35. Jonathan DQ (2001) Essential Drugs and Medicines Policy. Geneva, Switzerland: World Health Organization International Pediatrics Association.

36. Gidebo KD, Summoro TS, Kanche ZK, Woticha EW (2016) Assessment of drug use patterns in terms of the WHO patient-care and facility indicators at four hospitals in Southern Ethiopia: a cross-sectional study. BMC Health Services Research 16: 643.

37. Chima I, Obidiya O, Abraham C (2012) Evaluation of drug use and patient care practices in a referral health facility in yenagoa, bayelsa state, Nigeria. Cont J Pharm Sci 6: 10-16.

38. Arustiyono (2015) Promoting rational drug use at the community health centers in Indonesia.

39. MoHCW-Public Sector Survey (2000) Harare, directorate of pharmacy services, Ministry of health and child welfare, Zimbabwe.

40. Tamuno I (2011) Prescription pattern of clinicians in private health facilities in Kano, Northwestern Nigeria. Asian Pac J Trop Dis 1: 235-238. 